Revista Água Viva

ISSN 1678-7471

\title{
PRODUÇÃO DE SUBJETIVIDADES E A REPRODUÇÃO DO MESMO EM GAIBÉUS, DE ALVES REDOL
}

\section{PRODUCTION OF SUBJECTIVES AND THE REPRODUCTION OF THE SAME IN GAIBÉUS, BY ALVES REDOL}

João Silveira Muniz-Neto ${ }^{1}$

Recebido em:

Aceito em: 19 out. 2018

DOI 10.26512/aguaviva.v3i3.22116

RESUMO: Objetivamos apresentar uma leitura da obra Gaibéus (1989), do português Alves Redol, sob o prisma das Filosofias da Diferença (através de autores como Foucault, Deleuze e Guattari), oferecendo a noção de produção de subjetividades e mostrando como esta produção, na obra ora em estudo, é executada de forma a homogeneizar os indivíduos, reproduzindo o mesmo, produzindo-os sem resguardar espaços para a singularização.

Palavras-chave: Gaibéus; Alves Redol; Produção de subjetividades; Singularidade; Linhas de fuga.

ABSTRACT: We aim to provide a reading of the work Gaibéus (1989), portuguese Redol Alves, from the perspective of the Philosophy of Difference (by authors such as Foucault, Deleuze and Guattari), offering the notion of subjectivity production and showing how this production, in the work under study, is performed to homogenise individuals, reproducing the same, producing them without reserved space for singularization.

Keywords: Gaibeus; Alves Redol; Subjectivities productions; Singularity; Lines of escape.

\section{INTRODUÇÃO}

Alves Redol, já em seu texto de inauguração literária, Gaibéus (1989), implanta um novo movimento na literatura portuguesa - chamado Neorrealismo. Inicialmente, segundo o

\footnotetext{
${ }^{1}$ Graduação em Psicologia (2011) e mestrado em Psicologia (2014) pela Universidade Federal do Ceará (UFC). Doutorando em Educação pela UFC. Professor no Centro Universitário INTA (UNINTA). E-mail: netomuniz15@yahoo.com.br
} 
próprio autor, a obra que lhe permite, pela primeira vez, o título de escritor, originalmente, não seria de literatura, mas um estudo sócio demográfico sobre uma espécie de trabalhadores que, a todo ano, cruzavam algumas milhas de distância a fim de buscar o próprio sustento, deslocando-se do Alto Ribatejo e da Beira Baixa rumo às Lezírias do Tejo, chamados gaibéus. Já no início do livro temos este preâmbulo, quando Redol nos diz sobre o coletivo que narrará: “Do Alto Ribatejo e da Beira Baixa eles descem às Lezírias pelas mondas e ceifas. Gaibéus lhes chamam" (REDOL, 1989, p. 05).

Redol, ao descrever suas personagens em Gaibéus (1989), soube mostrar a marginalização das mesmas, exploradas à máxima carga de suas forças físicas, de tal sorte que não temos muitos argumentos, a tomar como referência apenas tal obra, para diferenciarmoslhes de outros animais. Devido ao seu comprometimento social ${ }^{2}$, o escritor nunca se viu livre da censura e travou "uma grande batalha individual contra os coronéis da Mesa Censória, que nunca venceu” (TORRES, 1979, p. 17). Redol não pôde com a força avassaladora da censura, todavia criou artifícios que lhe possibilitaram driblar a perseguição censória da ditadura salazarista: como não podia escrever diretamente sobre as repressões e problemas sociais, mostrou como isso acontecia. Dessa forma, sem precisar escrever sequer uma linha criticando explicitamente a política do governo - e precisamente por isso, escrevendo obras literárias que faziam resistência ao modo de operar da ditadura - o escritor resistiu, mostrando como os pobres de Portugal viviam, utilizando, como personagens, os gaibéus, em seu livro de estreia.

Gaibéus (1989), como o próprio título parece indicar, encerrará um grupo como protagonista principal, não tendo personagens específicos como foco narrativo, mostrando, justamente, a identidade dos sujeitos menos socialmente favorecidos das sociedades lusas. Muitos indivíduos são ditos, não por si, mas a partir da descrição de um grupo (os gaibéus). Contudo, uma considerável parcela sente-se, de forma incorrigível, identificada com as descrições feitas por Redol (1989), de modo que, mesmo descrevendo um personagem, em última instância, coletivo, são de indivíduos específicos - (com gostos, desgostos, sonhos e lutos idiossincráticos) a quem a pena crua de Redol (1989) está referindo-se.

\footnotetext{
${ }^{2}$ Alves Redol é de clara influência marxista. O marxismo, pela época em que o livro veio à baila (1939), era quase que uma leitura obrigatória aos intelectuais, o que lhes conferia, muitas vezes, uma espécie de exibível para determinados grupos e agremiações organizadas por estes mesmos intelectuais. Hoje, apesar de a grande e inegável força que podemos presenciar da teoria marxista - e, não raro, seu muito mal-uso pelo senso comum! - pode-se apontar alguns autores que lhe impuseram (à teoria marxista) críticas, delimitações e/ ou superações tais como Foucault (1982), Arendt (1993), Deleuze (1996), Guattari (2008) e, em alguma medida, mesmo alguns vultos da Escola de Frankfurt, como Adorno \& Horckeimer (1985).
} 
Pela primeira vez, com Redol (1989), os gaibéus, têm presença efetiva dentro da literatura portuguesa. Mendonça (1973, p. 99) chama a atenção para a "despersonificação violenta" que sofreram os protagonistas na maioria dos romances portugueses do decênio de 1940. Os grandes personagens dos romances neorrealistas de expressiva atuação são os patrões e os empregados, de uma gritante influência exercida pelo marxismo, então em voga ${ }^{3}$.

Não obstante, alguns indivíduos são destacados na obra. É precisamente este destaque operado por Redol em algumas personagens femininas o que nos permite tecer análises sobre algumas figuras dramáticas da obra, nas últimas sessões deste.

A despeito do viés marxista do autor de Gaibéus (1989), tentaremos efetuar uma análise que se paute pelas Filosofias da Diferença, dentro das quais a ideia de produção de subjetividades tem característica nuclear. Passemos a este tema na próxima sessão.

\section{Produção de subjetividades em Gaibéus}

Como o autor Alves Redol tem um forte teor tomado de empréstimo ao marxismo, cumpre, neste trabalho, fazermos uma breve explanação da teoria marxista e das ideias de alguns autores pós-Marx.

A teoria marxista entende o mundo a partir de dicotomias. A mais famosa destas é a díade entre opressores e oprimidos. De acordo com tal teoria, seria exatamente a "tomada de consciência do proletariado" (por proletariado entenda-se qualquer classe social socialmente oprimida) o que permitiria aos explorados tomar as rédeas do funcionamento social e dirigir a sociedade rumo ao socialismo para, por consequência, chegar ao comunismo ${ }^{4}$. Outra dicotomia fundamental à teoria marxista é a de estrutura x superestrutura. A primeira balizaria o funcionamento econômico, ao passo que, a cargo da segunda, ficariam os ditos processos abstratos, ou as ideologias. Portanto, a forma de funcionar e operar de qualquer sociedade seriam à égide do plano demarcado pelo funcionamento a nível econômico (ALTHUSSER, 1999).

\footnotetext{
${ }^{3}$ É sabido que o Regionalismo de 30, efetuado na literatura brasileira, cumpriu - numa espécie de colonização às avessas - uma forte influência sobre as letras do Neo-Realismo português.

${ }^{4}$ Eis aqui uma crença mítica, na qual se crê que as sociedades humanas caminham, linear e matematicamente, para frente, sustentadas pela lógica do progresso, a fim de um futuro comum e que o comunismo seria isento de relações de poder e, como tal, de opressão.
} 
Guattari (in: GUATTARI \& ROLNIK, 2008, p. 21) diz, contudo, que "é a própria essência do lucro capitalístico que não se reduz ao campo da mais-valia econômica: ele está também na tomada de poder da subjetividade". O funcionamento das sociedades, na óptica guattarinina, não se reduziria aos mecanismos operacionais do nível econômico, remetendo, sobretudo, a um controle sobre a forma de agir e pensar dos indivíduos; pois é a nível da subjetividade que o poder se exerce. Por isso, a ideia de produção social de subjetividades, tão cara à Filosofia da Diferença (que tem nas figuras de Michel Foucault, Felix Guattari e Gilles Deleuze seus principais expoentes). Nesta perspectiva, Guattari (idem, p. 36) afirma que "a produção de subjetividade constitui matéria-prima de toda e qualquer produção".

Se o marxismo traz a noção de ideologia como responsável pelo setor abstrato da consciência de cada indivíduo, os filósofos da diferença optam por propor uma lógica diferente, na qual as subjetividades seriam produzidas em série e em larga escala a nível mundial e porque sutil - com uma força operativa muito maior e mais eficiente do que a das supostas "ideologias" que, por lhes serem externas, teriam que ser introjetadas posteriormente (numa espécie de inculcação) nos indivíduos. Assim,

a noção de ideologia não nos permite compreender essa função literalmente produtiva da subjetividade. A ideologia permanece na esfera da representação, quando a produção essencial do CMI [Capitalismo Mundial Integrado] não é apenas a da representação, mas a de uma modelização que diz respeito aos comportamentos, à sensibilidade, à percepção, à memória, às relações sociais, às relações sexuais, aos fantasmas imaginários, etc. (idem, p.36).

Trocando em miúdos, para os Filósofos da Diferença (com esta expressão, neste estudo específico, referimo-nos a Deleuze, Foucault e Guattari) a produção que o capitalismo opera incide diretamente sobre aquilo que nos faz humanos: nossa subjetividade. Neste sentido, as subjetividades - produzidas massivamente - deixam de ser encaradas como uma essência ou uma coisa em si e passam a ser entendidas como produtos de agenciamentos coletivos de enunciação. Com efeito, a própria noção de $e u$, de sujeito - em vez da noção imanente que temos destes - têm toda uma produção maquínica:

a concepção ocidental da pessoa como um universo cognitivo e emocional delimitado, único e mais ou menos integrado; como um centro dinâmico de consciência, emoção, juízo e ação; organizado em uma totalidade distintiva que está conformada em contraste a outras tonalidades como ela e em 
contraste a outras totalidades como ela e em contraste também a um fundo natural e social é, apesar de todo o incorrigivel que nos possa parecer, uma ideia bastante peculiar no contexto das culturas do mundo (Gerhz apud Larrosa, 2020, p. 42, grifos nossos).

Precisamente a noção de produção social da subjetividade configura-se como uma das categorias limítrofes das Filosofias da Diferença em relação a certa "imagem de pensamento" (Deleuze, 1988) que se possa fazer sobre a teoria marxista.

Diante do exposto, é lícito, portanto, afirmar, trazendo novamente o fio da argumentação à obra de Redol, que existe a descrição de uma produção de subjetividades homogêneas na obra Gaibéus (1989), na qual todos os indivíduos (suas individualidades, seus desejos, seus medos, suas aspirações etc) são produzidos massivamente, homogeneamente, de forma equalizadora e sem espaços para que se emerjam aquilo que Guattari denominou de processos de singularização, Foucault de resistência e Deleuze, de linha de fuga $a^{5}$. Os gaibéus são nada mais que um grupo e, ao que parece, não conseguem suster-se fora da alusão a este grupo.

Estes termos utilizados por estes autores referem-se a formas singulares de viver. Diz de um movimento de resistência a tornar-se igual (e a ser tornado igual) às vidas já vividas. Alude a linhas de fuga a dispositivos - que balizam nossas existências e agenciam-nos de forma a apresentarmos vida sem criatividades, existências sem resistências -; a indicações de novas formas de existir, de viver e de ser; a recusas do estabelecido, do convencionado, do mesmo.

Em alguns episódios, Redol (1989) expõe um tipo de movimento político que podemos entendê-lo, se não como uma resistência ao modelo de produção homogêneas de subjetividades, uma fuga a ele: seria, literalmente, a fuga das Lezírias através do mar, para terras distantes e conhecidas dos gaibéus apenas por sonhos e delírios. Todo um capítulo da obra ("Porto de todo o mundo") é dedicado a este modelo de fuga desta realidade ${ }^{6}$.

À figura do ceifeiro rebelde (personagem autobiográfica, confessada pelo próprio Redol no prefácio do livro), a nosso ver, não se pode atribuir o caráter político de resistência, já que o personagem, apesar de fazer o exame mais lúcido da situação em que ele e seus iguais

\footnotetext{
${ }^{5}$ Para maiores informações sobre o termo processos de singularização, cf. Guattari \& Rolnik (2008). Foucault utiliza o termo resistência; fazendo as (in)devidas traduções entre as obras dos dois autores, podemos dizer que remetem à mesma noção política, cf. em Foucault (2009b) e Foucault (2009c). Deleuze (1996) utilizou o termo linha de fuga, para designar algo, politica e funcionalmente, parecido em seus textos.

${ }^{6}$ É bom deixar claro que o que estamos fazendo aqui é uma leitura da obra a partir de uma óptica específica (as ideias correntes nas Filosofias da Diferença) e que Alves Redol via o mundo a partir de uma outra lente (o marxismo). Para o autor da obra, a união entre gaibéus e rabezanos (outro grupo de alugados, parecidos com aqueles) - já que "na fome os rabezanos não diferiam dos gaibéus", (REDOL, 1989, p. 78) - seria suficiente para pôr fim ao regime escravocrata que ambos os coletivos encontravam-se submetidos.
} 
encontram-se, efetiva e politicamente, nada faz para resistir a este modelo, consentindo, em última análise, com este.

Os gaibéus não vivem, cumprem um fado; fado este que já foi cumprido por seus antepassados que já morreram e, em tempo presente, é desempenhado pelos gaibéus mais velhos, que dão as balizas do viver para os mais jovens. Há toda uma produção de modos de viver e de se operar sobre o mundo: tudo parece já anteriormente dito, pré-fabricado, já marcado, sem a possibilidade de emergência do novo, do desigual, da ruptura, do não-dito e do ainda não-vivido. A vida é uma mera repetição do pretérito. $\mathrm{O}$ excerto que agora exibimos é especialmente emblemático para ilustrar o que estamos expondo: "A figura de Ti Maria do Rosário, dobrada e trêmula, torna-lhes [aos gaibéus] mais penoso o trabalho. [...] Cada um conhece nela o futuro que lhes baterá a porta, um dia" (REDOL, 1989, p. 91, grifos nossos).

Podemos fazer um paralelo entre a vida dos gaibéus e um famoso poema de João Cabral de Melo Neto, intitulado Morte e Vida Severina ${ }^{7}$, na qual conta-se a história de Severino, um indivíduo natural do interior do Nordeste brasileiro que, por conta de seu destino anteriormente previsto, tem toda uma dificuldade para, ainda no início do poema, inclusive, dizer quem é, pois muitos - "iguais em tudo e na sina" - dos seus concidadãos têm lhe um destino tão parecido e igual, um viver tão desditoso e pouco singular que uma dificuldade de dizer-se instala-se. Diante de tantas sortes iguais - nomes, locais de nascimento, laços de paternidade - assim, o protagonista se pergunta: "Como então dizer quem falo ora a Vossas Senhorias?". Assim, destacamos este excerto para melhor desenhar o cenário que estamos tentando descrever:

\author{
- O meu nome é Severino, \\ como não tenho outro de pia. \\ Como há muitos Severinos, \\ que é santo de romaria, \\ deram então de me chamar \\ Severino de Maria. \\ Como há muitos Severinos \\ com mães chamadas Maria, \\ fiquei sendo o da Maria \\ do finado Zacarias. \\ Mais isso ainda diz pouco: \\ há muitos na freguesia, \\ por causa de um coronel \\ que se chamou Zacarias \\ e que foi o mais antigo
}

\footnotetext{
${ }^{7}$ Antônio da Costa Ciampa tem, em sua tese de doutoramento, o título A Estória do Severino e a História da Severina, na qual trata - apesar de tomar por baliza teórica outros autores dos que aqui apresentados - justamente, da homogeneização de modos de vida a partir do poema de Melo-Neto, conforme Ciampa (1987).
} 
senhor desta sesmaria. Como então dizer quem falo ora a Vossas Senhorias? Vejamos: é o Severino da Maria do Zacarias, lá da serra da Costela, limites da Paraíba.

Mas isso ainda diz pouco: se ao menos mais cinco havia com nome de Severino filhos de tantas Marias mulheres de outros tantos, já finados, Zacarias, vivendo na mesma serra magra e ossuda em que eu vivia.

Somos muitos Severinos iguais em tudo na vida: na mesma cabeça grande que a custo é que se equilibra, no mesmo ventre crescido sobre as mesmas pernas finas e iguais também porque o sangue, que usamos tem pouca tinta. E se somos Severinos iguais em tudo na vida, morremos de morte igual, mesma morte severina: que é a morte de que se morre de velhice antes dos trinta, de emboscada antes dos vinte de fome um pouco por dia (de fraqueza e de doença é que a morte severina ataca em qualquer idade, e até gente não nascida). (...)

Mas, para que me conheçam melhor Vossas Senhorias e melhor possam seguir a história de minha vida, passo a ser o Severino que em vossa presença emigra (MELO-NETO, 2000, p. 43).

Podemos, não sem alguma violência, cotejar as figuras de Severino, descrito por Melo Neto (2000), e os gaibéus, personagens de Redol (1989). Ambas as figuras são agricultores do interior de seus países; ambas explorados por seus patrões (inúmeros durante a vida: desde o senhor que lhe compra os serviços até os capatazes, passando por padres, políticos, etc.); ambas têm dificuldade para identificarem-se enquanto um indivíduo, são despersonalizados à revelia de seus quereres. Mesmo em Severino, que lhe tem todo um poema dedicado, esta 
despersonalização é cruamente apontada sempre que este tenta identificar-se, como bem pode ser atestado no excerto acima.

Algo que pode ser apontado como uma diferença entre os personagens "criados" pelos autores é que o escritor brasileiro, ao descrever um indivíduo (Severino) em meio a uma massa, torna-os iguais (a massa) entre si, o luso optou por descrever um coletivo de indivíduos, que, em seu processo de descrição, contempla todos os gaibéus, individual e homogeneamente.

\section{A presença do mesmo a partir de análises de algumas personagens em gaibéus}

Em Gaibéus (1989) toda uma produção de subjetividades homogêneas das personagens é sustentada por mecanismos como a desumanização das condições de trabalho a que são submetidos os gaibéus; na instalação do "conformismo" que é inculcado a cada um, garantido por relações semióticas; na metamorfose dos personagens em condição maquinizada, em detrimento de seu caráter humano; em sua perene despersonalização, agenciamentos maquínicos de homogeneização; em produções de um viver pouco criativo e que pouco instaura ou reserva espaço para o novo, para a diferença e para a singularização;

Já no início da narrativa, Redol (1989) expõe a figura de uma anciã que cai por terra, mostrando toda a animalização sofrida por seus personagens, permitindo-nos a inferência de que estes são definidos a partir de categorias que os perfilam muito mais a outros animais que a outros seres humanos (exceção, no excerto abaixo, ao fato de a velha rezar e de chorar manso).

\footnotetext{
Uma velha deixou-se cair no valado, a tossir e a rezar. Os membros aquebrantados pareciam ter-lhe abandonado o corpo e ali fica sem forças para ir no rastro do rancho. Agatanhando as ervas, subiu ao alto do valado e sentouse, como se ali procurasse refúgio. Espraiou os olhos pela campina fora, mas sentiu-se só. Só como nunca, derribada na alma. E a velha chorou num pranto manso (REDOL, 1989, p. 62).
}

Na passagem abaixo, podemos perceber, em uma fala da personagem Ti Maria do Rosário, a inculcação do dever de trabalhar, pois a vida dos gaibéus é o próprio trabalho. Viver para trabalhar e conseguir suster-se durante o inverno quando não há trabalho. Trabalhar para sobre-viver; antes, viver é trabalhar: a ceifa é o pão!

\footnotetext{
- Então Ti Maria do Rosário?! ...

- Hum?!

- Sente-se doente?! ... Vá um quartel para o barracão...
} 
O corpo da velha sacode-se num estremecimento de pânico quando o capataz lhe fala em descansar.

Nem para ela nem para os companheiros a ceifa pode parar - a ceifa é o pão. $[\ldots]$

O cérebro diz-lhe que deve ir para junto deles, e depressa, mas as pernas já não obedecem ao seu mando. O capataz segura-lhe os braços magros e tiralhe a foice.

- Isso não, Manel! ... Isso não!... - clama a Ti Maria do Rosário num desespero.

O corpo treme-lhe, os olhos gotejam. Levanta as mãos numa súplica, não percebe o que faz e depois luta com o homem, desesperada.

- Ó Manel!... A foice... dá-me a foice!... (idem, p. 90).

Ora, este comportamento de Ti Maria do Rosário demonstra, claramente, sua assonância e sua anuência com a ordem estabelecida, a favor dos agenciamentos proclamados e já ditos, pois, mesmo que cegamente, quanto mais ela trabalhasse - e produzisse para Agostinho Serra, o patrão - mais se solidificaria em sua condição de pessoa explorada e, por conseguinte, justificaria, a nível individual, a qualificação de Agostinho Serra para postar-se como o empregador.

Os gaibéus, além de tomarem água no mesmo poço que as éguas, todos a tomam no mesmo cântaro, indicando a supervisão do mesmo destino. Essa indicação pode ser observada no sofrimento dos gaibéus, e da própria Ti Maria do Rosário, ao verem o que aconteceu a esta, quando acometida de sezão. A velha desespera-se quando o capataz lhe pede para deixar a ceifa. É uma cena angustiante, seu corpo já não aguentava trabalhar, mas ela sabia que, se parasse, não teria quem lhe desse o pão no inverno. A ceifa não pode parar: a ceifa é o pão!

Ao mostrar o processo exploratório, em níveis que, desumanizando, animaliza o homem, Redol (1989) fez referência ao procedimento histórico que estava se processando em Portugal, durante o regime salazarista, que explorava o trabalhador rural, principalmente no período entre as duas Grandes Guerras Mundiais, quando exportou produtos agrícolas aos países europeus. A denúncia foi feita de forma - sutil - a não pronunciar uma única palavra contra esse sistema. O autor usou um discurso para camuflar um outro - silêncio constituído.

Redol (1989), ao confiarmos-lhe crédito a sua própria introdução à obra, não tinha intenção de que sua arte revolucionasse o mundo. Seu mérito reside precisamente em ter conseguido mostrar o que acontece, a nível psicológico, com seus personagens, submetidas aos rigores de um sistema equalizador, que os torna iguais em seu viver. Eis uma turva fotografia de Gaibéus. 


\section{Análises de algumas personagens}

Embora o romance de Redol (1989) seja eminente sobre um personagem coletivo, há a possibilidade de discernirmos alguns personagens gaibéus em destaque em relação à gleba descrita na narrativa: uma ceifeira jovem, chamada Rosa; uma ceifeira idosa, chamada Ti Maria do Rosário; uma ceifeira adulta (ceifeira sem nome), abandonada pelo marido, com um filho para criar, que não possui nome na narrativa (FILLUS, 2002), bem como um ceifeiro que conhece locais de além-mar, o ceifeiro rebelde, entre outros.

Para ilustrar nosso intento neste trabalho, passemos, pois, a uma sucinta análise de 03 personagens femininas destacadas na obra Gaibéus (1989). Justificamos a escolha pelo fato de vermos traçado um ciclo entre as personagens destacadas para análise: Ti Maria do Rosário, a ceifeira idosa; Ceifeira Sem Nome, a ceifeira adulta; Rosa, a ceifeira jovem. Tais personagens são idênticas em suas trajetórias, o que se caracteriza de modo diferente é a faixa etária em que se encontram, mas - é o que Redol (1989) parece insinuar - será repetitiva a saga de cada uma...

\section{Ti Maria do Rosário}

Ti Rosa do Rosário é uma ceifeira idosa, com visível debilidade física, que, sem embargo, precisa ceifar diariamente, assim como qualquer outro gaibéu, uma cota préestabelecida a fim de que tenha o montante para seu sustento. Porém sua já debilitada condição física a deixa em desvantagem em relação aos demais: "O cérebro diz-lhe que deve ir para junto deles, e, depressa, mas as pernas já não obedecem ao seu mando” (idem, p. 91).

Quando esta cai doente e, assim mesmo, não quer parar a ceifa, Redol diz que "nem para ela, nem para os companheiros, a ceifa pode parar. A ceifa é o pão ${ }^{8}$." (idem, p. 90). A condição da personagem - neste caso, a personagem coletiva que o livro descreve, os gaibéus - igualado à categoria de máquina, máquina esta que não pode estragar nem parar de produzir, pois representa um capital investido pelo patrão, que obrigatoriamente quer o retorno - conseguido através da produção dos alugados (gaibéus).

Toda a existência é um ciclo diante do qual cada ceifeira tem ciência de que a vida termina de forma idêntica, ou seja, vencer a debilidade física diante da necessidade preeminente

\footnotetext{
${ }^{8}$ A frase "a ceifa é o pão" aparece, na narrativa, nada menos que seis vezes, encontradas nas páginas 90 (repetidas 3 vezes), 91, 100 e 114, o que pode nos dar a ideia da vida dos gaibéus: antes de viver, estes trabalham; trabalham não para sustentarem-se, mas para (sub)viver. Um ciclo do qual todos são reféns, ficando presos a destinos e fados que apenas reproduzem o já vivido, o já estabelecido, o mesmo.
} 
de produção, já que "a ceifa é o pão": Reexibimos a citação referente a Ti Maria do Rosário, quando esta cai doente: "A figura de Ti Maria do Rosário, dobrada e trêmula, torna-lhes mais penoso o trabalho. [...] Cada um conhece nela o futuro que lhes baterá a porta, um dia" (REDOL, p. 91, grifos nossos).

\section{Rosa}

Em oposição a Ti Maria do Rosário, que é idosa, na obra de Redol (1989) aparece Rosa, que é moça. Seus destinos, contudo, tendem a ser semelhantes, pois, enquanto for jovem e tiver a força para o trabalho ou a beleza, Rosa pode ser desejada e explorada pelos homens. Todavia quando a rigidez e o frescor do corpo forem embora, junto com suas forças na lida da ceifa, Rosa entrará em contato com um destino muito parecido com o de Ti Maria do Rosário e de outras tantas gaibéuas que lhe sucederam.

Precisamente por seu corpo bonito e vistoso, Rosa passa a atrair a atenção do sexo oposto. Nas mondas, aparece o desejo de cobiça e de posse do capataz (Francisco Descalço). Diante desta situação, Rosa permanece impotente, sofrendo o assédio moral e sexual no trabalho: "A rapariga meteu-se entre as outras, a cortar e a engavetar. Os mosquitos picam-na menos, porém que os olhos do capataz" (idem, p. 43).

Rosa chegou com sonhos à colheita, deixando um namorado em sua terra de origem, contudo logo entra em contato com uma realidade perversa, que lhe dá a caução do seu futuro: assédio, prostituição, ceifa, sonhos dessonhados... Inicia-se a anulação de seus sonhos e será mais uma que repetirá a saga descrita por Redol, atestando a produção homogênea de subjetividades (Guattari \& Rolnik, 2008), na qual as criaturas padecem sob determinada forma de viver em detrimento de formas de vida criativas e singulares. Na citação que segue, é descrito como Rosa sentiu-se ao ser levada para a casa de Agostinho Serra, patrão e dono da vida dos alugados: "Deu-lhe ganas de atirar a foice e abalar. Se fosse junto dele, não seria a Rosa do rancho do Francisco Descalço. Seria a Balbina da Rua Pedro Dias, noiva de todos que mercassem afagos" (REDOL, 1989, p. 104).

Em tempo: Balbina era o protótipo de uma mulher gaibéua que "caiu na vida". O fato de poder ser equiparada à prostituta lhe rende muitas angústias, em um momento da narrativa em que o psicologismo fica patente, com o autor nos fazendo entrar em contato com os pensamentos da moça: "Tinha os olhos tristes e chamava-se Balbina - Balbina da Rua Pedro Dias" (idem, p. 104).

Rosa, a ceifeira jovem, com sonhos por vir, vê-se presa a um fado que é seu jugo e fardo. Ao encontrar-se na casa de Agostinho Serra, percebe-se moralmente desvalorizada e sente-se suja por ter juntado dinheiro de forma diferente das outras gaibéuas: "Ela sabia que se perdera para o mundo e não 
era a mesma mulher vinda à emposta para ganhar o sustento. Tinha no saco mais dinheiro que as companheiras e não o juntara no sol a sol da ceifa" (REDOL, 1989, p. 165).

Assim o pensamento que lhe doma as angústias faz-se presente de forma avassaladora na vida de Rosa: "Não seria Rosa o seu nome chamar-lhe-iam Balbina" (idem, p.165). Sua identidade enquanto pessoa estaria presa à de uma figura quase lendária, mas que, assim mesmo (ou por isso mesmo!) tornase cotidiano e é um elemento inerente à vida de azáfama das gaibéuas.

\section{A ceifeira sem nome}

A terceira personagem destacada neste trabalho- cumprindo seu destino igual ao de tantas outras já finadas gaibéuas, com a existência re-marcada pelo mesmo, pelo igual, pela reprodução, sem espaços para a criatividade - aparece na narrativa apenas como a "ceifeira sem nome", a mulher comum que sonha, que se apaixona, vive um romance, tem um filho e é abandonada pelo amante - exatamente por não nomeá-la, mas por fazer dela um arquétipo, Redol (1989) amplia seu destino a tantas outras gaibéuas. Eis o retrato mais fiel que o autor nos dá de sua personagem: "era uma gaibéua de olho azul que nem a flor do almeirão. Desenxovalhada e bonita de cara que nem uma Nossa Senhora” (idem, p. 60).

O resultado, ou as consequências de sua vida-guardando extremas similitudes com uma peça de teatro repetida e contracenada durante anos a fio, sem que o diretor dê-se o trabalho de rever o texto, o figurino, o ambiente etc. - é que, terminada a ceifa, a narrativa acaba-se e o autor sugere que a gaibéua de olho azul vai regressar à terra onde nascera, para voltar, ao ano vindouro, às Lezírias, de filho nos braços, faminta, desprezada, largando na nova ceifa os últimos pedaços dos pulmões...

A ceifeira sem nome, que significa, metaforicamente, o anonimato, não tem expressividade enquanto indivíduo, mas representa todas as mulheres que caminham, cumprindo o eterno fado, portanto, cumprindo o eterno destino ao qual estão submetidas e expostas (FILLUS, 2002). Ela opera sua forma de viver sob o protótipo que confere identidade a uma grande parcela de mulheres, que são impedidas de concretizar os sonhos, pois, ao que parecem, cumprem (e não vivem!) um destino que, por lhes ser anterior, já lhes é traçado e conhecido, ou seja, conviver com a solidão, filhos para sustentar e criá-los em condições subumanas, já que as gaibéuas sempre seriam exploradas até o máximo de suas exaustões, de suas capacidades e de suas forças sem ter, quase sempre, alguém que as ampare: "Tinha ficado só - só com os seus sonhos" (idem, p. 53). 


\section{Paralelo entre as três Personagens}

É possível estabelecer um paralelo entre as personagens Ti Maria do Rosário, Rosa e A ceifeira sem nome, no qual a retrospecção de um passado (outras gaibéuas anteriores, reféns e vítimas de um fado hirsuto) e de um presente (Ti Maria do Rosário) é (re)dimensionada para uma perspectiva de futuro para as outras duas personagens (Rosa e A ceifeira sem nome), no qual refletir-se-á a trajetória que cada uma percorre(rá) e passivamente cumpre(irá), tal como se fossem animais (REIS \& LOPES, 1993).

Ainda é possível detectar o abandono dos filhos que, involuntariamente, as mulheres são obrigadas a realizar, uma vez que possuem jornadas diárias de longo trabalho. Portanto, os filhos ficam à mercê deles próprios e das contingências ambientais, indefesos, tais como se fossem animaizinhos, somente à espera da alimentação materna:

Já as mulheres que deixaram os filhitos ao abandono por ali os apertam entre os braços e os animam, beijando-lhes as faces sujas de terra, amassada com lágrimas. E eles buscam-lhes com as bocas rebentadas de feridas, onde as moscas pousam e o ranho criou crosta, os peitos escorridos, beliscando-lhes nas blusas a sua fome (REDOL, 1989, p. 47).

Redol (1989), em seu romance, reifica três personagens femininas que simbolizam uma época. Fica como denúncia para a humanidade, em que se evidencia a problemática sofrida pela jovem, pela mulher e pela anciã, pelos gaibéus, enfim. Forma, pois, uma cadeia de sequências nas células narrativas que, individualmente, passarão na trajetória existencial dos gaibéus - e, por extensão, de muitas etnias, culturas e credos mundo afora.

\section{À GUISA DE CONCLUSÃO}

Para terminar este trabalho - sempre com reticências, nunca com ponto final - queremos fazer um novo paralelo, agora entre as figuras femininas destacadas da narrativa de Redol (1989) e uma canção de Chico Buarque de Holanda, ei-la:

\section{MULHERES DE ATENAS}

Mirem-se no exemplo daquelas mulheres de Atenas vivem pros seus maridos, orgulho e raça de Atenas 
quando amadas, se perfumam se banham com leite, se arrumam suas melenas.

Quando fustigadas não choram, se ajoelham, pedem imploram mais duras penas; cadenas. Mirem-se no exemplo daquelas mulheres de Atenas sofrem pros seus maridos, poder e força de Atenas

Quando eles embarcam soldados elas tecem longos bordados; mil quarentenas. e quando eles voltam, sedentos querem arrancar, violentos carícias plenas, obscenas

Mirem-se no exemplo daquelas mulheres de Atenas despem-se pros maridos, bravos guerreiros de Atenas. Quando eles se entopem de vinho costumam buscar um carinho de outras falenas mas no fim da noite, aos pedaços quase sempre voltam pros braços de suas pequenas, Helenas.

Mirem-se no exemplo daquelas mulheres de Atenas: geram pros seus maridos, os novos filhos de Atenas. Elas não têm gosto ou vontade, nem defeito, nem qualidade; têm medo apenas.

Não tem sonhos, só tem presságios. O seu homem, mares, naufrágios... lindas sirenas, morenas.

Mirem-se no exemplo daquelas mulheres de Atenas temem por seus maridos, heróis e amantes de Atenas. As jovens viúvas marcadas e as gestantes abandonadas não fazem cenas. Vestem-se de negro, se encolhem, se conformam e se recolhem Às suas novenas; serenas Mirem-se no exemplo daquelas mulheres de Atenas secam por seus maridos, orgulho e raça de Atenas (BUARQUE \& BOAL, 1976).

O paralelo que nos pretendemos fazer é tentar mostrar que, tanto nas vidas das gaibéuas quanto nas vidas das atenienses, exerce-se uma vida massificada, marcada pela dor e desemparada por qualquer sorte de processo criativo - meras reprodutoras da vida de suas antepassadas. Se as atenienses devem seu principal jugo ao viver sob a égide de seus maridos, às gaibéuas cabe a azáfama de um viver que se confunde com as mondas, uma monda que é a própria vida das gaibéuas.

As atenienses, apesar de toda sua submissão e importância como sustentáculo da própria sociedade a que pertenciam, ficam relegadas às entranhas do olvido em favor de seus maridos ("orgulho e raça de Atenas"), a quem cabem todos os louros históricos da civilização grega; as gaibéuas, a despeito de sua força produtiva nas ceifas, tem seu modo de vida deslembrado, pelo 
julgamento da história oficial, precisamente por seu viver igual e homogêneo - todo seu esforço nas mondas reduz-se a escassos estímulos pecuniários e fica ocultado pelos verdadeiros ganhos financeiros do patrão.

A pouca criatividade da vida de mulheres gaibéuas e atenienses permite-nos inferir uma produção homogênea de subjetividades. São vidas que não escapam à poeira dos séculos, ficando perdidas nas engrenagens que fazem a roda do tempo girar, tornando necessário que surjam indivíduos singulares e com alta sensibilidade - como o autor da música exposta, Chico Buarque de Holanda e o autor da obra em estudo, Alves Redol (1989) - para darem cores diferentes a estas vidas, castigadas pela homogeneidade no pensar, no agir, no devaneiar, no sonhar...

Apesar do retrato que fizemos da produção subjetiva que há na obra Gaibéus (1989) não seríamos ingênuos a ponto de essencializar suas vidas e assegurar que tudo está pré-visto, prédito, pré-estabelecido. A despeito do aparente destino avassalador e determinante presente na obra ora em análise (e, inclusive, do tom quase essencialista que, por vezes, chegamos a tomar neste trabalho) afirmamos que a própria vida pode anunciar novas formas de existência, estabelecendo novos influxos, novos fluxos, novos caminhos e des-caminhos, recusas a existires homogeneizados, produzindo, inclusive, novos dispositivos.

Trocando em miúdos, nada impede que, no interior do funcionamento do dispositivo apresentado neste artigo, em suas amarras, em suas linhas constituintes - na medida em que este é constituído, também, pelos modos de existir dos seus personagens - a vida surja em formas de linha de fuga, que indicam modos de viver e condutas que fogem às cores anteriormente pintadas; nada impede que emerjam, em meio ao emaranhado de vidas iguais e fados vulgarmente instalados, formas de singularidade e vidas assentadas em processos de singularização; nada impede, por fim, que os gaibéus oponham-se ao mar de homogeneizações e equalizações ao qual estão banhados e gotas d'água dentro deste mesmo mar contraponhamse ao mesmo, ao comum e finquem modos de existência que destoem dos que usualmente foram estabelecidos.

[...] não é a própria vida, fazendo-se pulsar através de forças e fluxos decodificados e desterritorializados, ou de agregados intensivos, nômades, contingentes, incomensuráveis e imponderáveis que funciona do mesmo modo? [...] E não é justamente por esses motivos que a vida, assim entendida, escapa, foge e pode corporificar, dependendo de como são agenciadas suas 
potências, suas novas formas de resistência aos controlatos e mecanismos de dominação? (GADELHA, 2007, p. 26-27, grifos no original).

A máxima foucaultiana deve ser lembrada: onde há poder há resistência! Com efeito, nada impede que existam, em meio ao coletivo de gaibéus, resistências, já que estas se processam em plano molecular, na existência de cada um, no próprio processo de se ser, no existir.

\section{REFERÊNCIAS}

ADORNO, Theodor; HORKHEIMER, Max. Dialética do esclarecimento: fragmentos filosóficos. Rio de Janeiro: Jorge Zahar Editor, 1985.

ALTHUSSER, Louis. Infraestrutura e superestrutura. In: Aparelhos ideológicos de Estado. Lisboa: Editora Presença, 1999.

ARENDT, Hanna. A condição humana. Rio de Janeiro: Forense Universitária, 1993.

CIAMPA, Antônio da Costa. A estória do Severino e a história da Severina: um ensaio de psicologia social. São Paulo: Brasiliense, 1987.

DELEUZE, Gilles. Diferença e Repetição. Rio de Janeiro, Editora Graal, 1988;

FILLUS, Luiza Nelma. Perfis Femininos em Gaibéus de Álvares Redol. Analecta. Guarapuava - Paraná, v. 3, n. 2, p. 125-132, jul/ dez 2002.

FOUCAULT, Michel. Microfísica do poder. Rio de Janeiro: Ed. Graal, $3^{\text {a }}$ Ed., 1982.

FOUCAULT, Michel. História da Sexualidade I: a vontade de saber. São Paulo: GRAAL, 2009a.

FOUCAULT, Michel. História da Sexualidade II: o uso dos prazeres. São Paulo: GRAAL, 2009b.

FOUCAULT, Michel. História da Sexualidade III: o cuidado de si. São Paulo: GRAAL, 2009c.

GADELHA, Sylvio. Educação, políticas de subjetivação e sociedades de controle. Em: Marcondes, A., Fernandes, A., \& Rocha, M. (Orgs.) Novos possíveis no encontro da Psicologia com a Educação (pp. 15-36). São Paulo: Casa do Psicólogo, 2007.

GUATTARI, Felix \& Suely ROLNIK. Cartografias do Desejo. $9^{a}$ ed. Petrópolis, RJ: Vozes, 2008.

LARROSA, Jorge. Tecnologias do Eu e Educação. In: Silva, T. (Org.) O sujeito da

Educação: Estudos Foucaultianos (p. 35-86). Petrópolis: Vozes, 2002. 
HOLANDA, Chico Buarque de \& BOAL, Augusto. Mulheres de Atenas. Intérprete: Chico Buarque de Holanda. In.: Buarque, Chico. Meus Caros Amigos. São Paulo: LP (1976)/ CD (1989). Phonogram/ Phillips, faixa 2 - lado A.

MELO-NETO, João Cabral de. Morte e vida severina. In: Id. Morte e vida severina e outros poemas para vozes. 4. ed., Rio de Janeiro: Nova Fronteira, 2000. p. 43-80.

MENDONÇA, F. A literatura portuguesa no século XX. São Paulo: Hucitec, 1973.

REDOL, Alves. Gaibéus - 18 a ed. Lisboa: Caminho, 1989.

REIS, C. \& LOPES, A. C. M. Dicionário de teoria da narrativa. São Paulo: Ática, 2000. 